\title{
A formulação do Plano Estadual de Cultura da Bahia em análise ${ }^{1}$ Análisis de la formulación del Plan Regional de Cultura de Bahía The formulation of the State Culture Plan of Bahia in review
}

\author{
Sophia Cardoso Rocha²
}

\author{
Palavras-chave: \\ Plano Estadual \\ de Cultura da Bahia \\ Plano Nacional \\ de Cultura \\ Sistema Nacional \\ de Cultura \\ Políticas Culturais
}

\section{Resumo:}

O objetivo desse artigo é apresentar e analisar a trajetória de formulação do Plano Estadual de Cultura (PEC) da Bahia, no marco do Programa de Nacional de Fortalecimento Institucional dos Órgãos Gestores de Cultura, do Ministério da Cultura. A análise realizada ao longo do artigo baseou-se em documentos institucionais, estudos e pesquisas dirigidas a políticas públicas e na observação participante da autora. Como principais conclusões do artigo observou-se que: o processo de elaboração do PEC foi complexo e longo, acionando diversas instâncias e atores; a elaboração do PEC estava em total consonância com a política cultural desenvolvida pela Secretaria de Cultura do Estado da Bahia (Secult); havia um claro alinhamento político entre a Secult e o Ministério da Cultura, refletido nas diretrizes, ações e metas do PEC.

1 Texto recebido em 06/10/2019 e aceito para publicação em 23/10/2019.

2 Sophia Cardoso Rocha. graduada em Direito pela Universidade Católica do Salvador e em Produção em Comunicação e Cultura pela Universidade Federal da Bahia (UFBA). Possui mestrado e doutorado em Cultura e Sociedade pela UFBA e é pesquisadora do Centro de Estudos Multidisciplinares em Cultura (CULT) da UFBA, Brasil. Contato: sophiacrocha@gmail.com - https://orcid.org/0000-0003-3688-1228 


\section{Resumen:}

El propósito de este artículo es presentar y reflexionar sobre la trayectoria de la formulación del Plan Regional de Cultura de Bahía, en el marco del Programa Nacional para el Fortalecimiento Institucional de los Gestores Culturales del Ministerio de Cultura. El análisis realizado a lo largo del artículo se basó en documentos institucionales, estudios e investigaciones dirigidos a políticas públicas y la observación participante de la autora. Como conclusiones principales del artículo se observó que: el proceso de elaboración del Plan fue complejo y largo, desencadenando diversas instancias y actores; la elaboración del Plan estuvo totalmente en línea con la política cultural desarrollada por la Secretaría de Estado de Cultura (Secult); Hubo un claro acercamiento político entre Secult y Ministerio de Cultura, reflejada en las directrices, acciones y objetivos del Plan regional.

Palabras clave:

Plan Regional de Cultura da Bahía

Plan Nacional de Cultura

Sistema Nacional de Cultura

Políticas Culturales

\section{Keywords:}

State Culture Plan

National Culture Plan

Culture's National System

Culture Policy

\section{Abstract:}

This article aims to present and evaluate the State Culture Plan of Bahia (PEC) formulation path, within the framework of the National Program for the Institutional Strengthening of Cultural Managers, supported by the Ministry of Culture. This research is based on institutional documents, studies and investigations in the field of public policies and the author's participant observation. The analysis highlights some aspects as main conclusions: the PEC's development process was complex and long, triggering various instances and actors; the PEC's elaboration was totally in line with the cultural policy developed by the Secretariat of State for Culture (Secult); there was a clear political approach between Secult and Ministry of Culture, reflected in the PEC's guidelines, actions and goals. 


\section{A formulação do Plano Estadual de Cultura da Bahia em análise}

\section{Introdução}

Nas últimas duas décadas, as áreas da política e da gestão cultural no Brasil passaram por uma inédita mobilização em torno da instituição de elementos estruturantes, como mecanismos de participação social e instrumentos de planejamento de médio e longo prazo. Tal movimento se deu nos diversos níveis federativos que compreendem o Estado brasileiro - Municípios, Estados, Distrito Federal e União, e tiveram relação direta com uma ação intencional do Ministério da Cultura (MinC), que entre os anos de 2003 e 2016, com avanços e retrocessos, investiu na construção do Sistema Nacional de Cultura (SNC).

O impulso observado após os anos 2000 no sistema organizativo da cultura no país, especificamente no âmbito da gestão pública, deve ser compreendido no bojo do desenvolvimento do SNC, que, em síntese, pretende instituir na esfera federal e nos demais entes federados uma estrutura capaz de garantir estabilidade à área cultural por meio de: órgãos gestores; conselhos; conferências; comissões intergestores; planos; sistemas de financiamento; sistemas de informação e indicadores; programas de formação; e sistemas setoriais de cultura. (BRASIL, 2012) Conforme o Art. 216-A da Constituição Federal (1988), esse conjunto de elementos devem possibilitar a instituição de um

[...] processo de gestão e promoção conjunta de políticas públicas de cultura, democráticas e permanentes, pactuadas entre os entes da Federação e a sociedade, tendo por objetivo promover o desenvolvimento humano, social e econômico com pleno exercício dos direitos culturais. (BRASIL, 2012)
Uma pretensão difícil sob a mais diversas perspectivas, já que os elementos que devem compor os sistemas de cultura guardam em si enormes desafios para serem criados e desenvolvidos, sem falar no cenário de fundo brasileiro que reúne, concomitantemente, o histórico da fragilidade das políticas culturais, a complexa relação entre Estado e cultura, as desigualdades regionais que caracterizam o federalismo nacional e uma democracia jovem e instável.

Por outro lado, apesar desse cenário, há de se reconhecer o esforço do país em constituir políticas sistêmicas em diversas áreas, um movimento decorrente do modelo de federalismo cooperativo que convoca os entes federados a atuarem de maneira complementar. Assim, a Constituição Federal do Brasil de 1988 estabeleceu tanto competências privativas para os entes, como competências complementares e suplementares, quer permitem atuações conjuntas em diversas matérias, sem que o princípio da autonomia federativa seja violado. (ANDERSON, 2009; BARACHO, 1986) No Brasil, a prática de compartilhamento das competências em termos de prestação de serviços e promoção de atividades é tradicionalmente objeto de políticas sistêmicas, que, em resumo, têm por objetivo "promover a integração de órgãos, otimizar recursos, propiciar eficiência e universalidade do atendimento à população [...]" (CUNHA FILHO, 2010, p. 78). Neste sentido, áreas como saúde, educação, assistência social, meio-ambiente vêm se organizando para promover a atuação conjunta da União, dos Estados e dos Municípios.

Aprimeira experiência sistêmica no país e referencial para as demais é o Sistema Único de Saúde (SUS), fruto de uma intensa disputa capitaneada pelo movimento sanitarista, que desde a década de 70 pleiteava a universalização do acesso aos serviços de saúde e sua descentralização para os entes subnacionais. Esses e outros pleitos foram aprovados na VIII Conferência Nacional de Saúde, realizada em 1986, que estabeleceu os princípios do SUS consolidados em 1988 na Constituição Federal 
e na Lei 8.080/90: universalidade; descentralização político-administrativa; regionalização e hierarquização dos serviços; atendimento integral e participação da comunidade. (ARRETCHE, 2011; BRASIL, 1988; 1990) Desde então, uma série de normas e ações vem ocorrendo em torno do SUS, o que demonstra a sua complexidade e a necessidade de compreendê-lo enquanto processo de médio e longo prazo. Para a área da cultura, a organização do SUS foi uma clara referência, conforme depoimentos dos atores responsáveis pela condução do SNC no Ministério da Cultura e os elementos estruturantes do SNC, similares ao da Saúde, a exemplo de planos nacional, estaduais e municipais (ROCHA, 2018).

A experiência da construção de planos de cultura por parte de Estados e Municípios, processo induzido pelo MinC, deve ser entendido dentro desse contexto mais ampliado, que incorpora desafios do âmbito da cultura, do pacto federativo e da gestão pública.

\section{O Plano Nacional de Cultura e a sua pactuação}

Em 10 de agosto de 2005, foi aprovada a Emenda Constitucional n48 que acrescentou o parágrafo terceiro ao artigo 215 da Constituição Federal e previu a criação do Plano Nacional de Cultura "visando ao desenvolvimento cultural do país e à integração das ações do poder público [...]". (BRASIL, 2005). Tal previsão materializou-se por meio da Lei $n^{0} 12.343 / 2010$, que estabeleceu por um período de dez anos princípios, diretrizes, estratégias e ações para a cultura, bem como as atribuições do poder público. Neste caso, coube expressamente ao MinC a função de coordenação executiva do PNC, sendo responsável pelo estabelecimento de metas e pelos termos de adesão ao documento. Neste ponto, vale ressaltar que a vinculação de Estados, Distrito Federal e Municípios às diretrizes e metas do PNC deverá ser feita de maneira voluntária, em respeito ao princípio da autonomia federativa. Porém, por se tratar de um plano que não atende apenas à esfera federal, o PNC necessita que os três níveis federativos possam atuar de forma coordenada e colaborativa. O reconhecimento da dimensão federativa do PNC pode ser observado por meio de diversas metas que, para serem atingidas até 2020, precisam da atuação conjunta dos entes subnacionais, a exemplo de:

Meta 1: Sistema Nacional de Cultura institucionalizado e implementado, com 100\% das Unidades da Federação (UF) e 60\% dos municípios com sistemas de cultura institucionalizados e implementados.

Meta 37 - 100\% das Unidades da Federação (UFs) e $20 \%$ dos municípios, sendo $100 \%$ das capitais e $100 \%$ dos municípios com mais de 500 mil habitantes, com secretarias de cultura exclusivas instaladas.

Meta 49: Conferências Nacionais de Cultura realizadas em 2013 e 2017, com ampla participação social e envolvimento de $100 \%$ das Unidades da Federação (UFs) e $100 \%$ dos municípios que aderiram ao SNC. (BRASIL; MINC 2012)

A implementação de metas como essa exigem uma articulação entre todos os entes federados. Nesse sentido, é fundamental que o PNC e o SNC possam estar em sintonia e avancem nos processos de definição das competências e atribuições de cada ente, o que ainda não foi concretizado. Apesar da

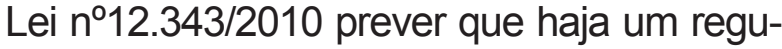
lamento tratando de tais aspectos, não houve a publicação do mesmo até o momento.

[...] apesar de a lei não limitar um tempo para que isso ocorra, a falta de um regulamento atravanca objetivos que demandam a capilarização das políticas em nível municipal e estadual, o estabelecimento de mecanismos de gestão e financiamento compartilhado de ações públicas e a própria interligação institucional com o Sistema Nacional de Cultura, principal responsável pela articulação federativa do Plano. (VARELLA, 2014, p. 166) 
O SNC, assim com o PNC, tampouco teve sua regulamentação publicada, o que prejudica o seu desenvolvimento. De acordo com Silvana Meireles (2017 apud ROCHA, 2018), o debate sobre o federalismo no âmbito do Sistema não avançou muito no MinC ou nos Estados e Municípios, o que prejudica a definição das competências, refletida na ausência das mesmas no PNC.

O federalismo como um dos pilares do SNC é um conceito reconhecido por todos. Contudo, o debate interno e mesmo com estados e municípios não avançou muito nesse sentido. Há pouco acúmulo desse debate. Tampouco houve progressos na discussão sobre os papéis e a divisão de responsabilidades entre os entes federados. O Plano Nacional de Cultura PNC é reflexo desse cenário: nas metas estabelecidas não há qualquer menção às competências das três esferas. (MEIRELES, 2017 apud ROCHA, 2018, p. 315)

Outro fator que agrava a implementação do PNC é o seu financiamento, posto que a Lei $n^{\circ} 12.343 / 2010$ prevê que, ao aderirem ao $\mathrm{PNC}$, os entes subnacionais receberão recursos públicos federais para desenvolverem suas ações. Tais recursos deverão ser transferidos da União para Estados e Municípios e serem aplicados prioritariamente através de Fundo de Cultura, com o devido acompanhamento e fiscalização do ConseIho de Cultura. Ocorre que o Fundo Nacional de Cultura não possui recursos suficientes para financiar ações previstas em planos de cultura dos entes subnacionais, aliás, nem mesmo para as ações do próprio MinC.

Muitas metas do Plano Nacional de Cultura não serão alcançadas por falta de financiamento porque a maioria das metas colocadas ali é de responsabilidade do governo de estados e municípios, nem é do Governo Federal. Além de serem metas ambiciosas para um prazo de 10 anos - quando você não resolveu certas questões do próprio Sistema [SNC]-, você pas- sa uma responsabilidade para estados e municípios quando eles não tem como suportar essa responsabilidade. (GUAPINDAIA, 2016 apud ROCHA, 2018, p. 315).

Todas as dificuldades acima relatadas não impediram o MinC de promover ações voltadas à participação dos entes subnacionais no PNC e no SNC. Nessa perspectiva, foi criado em 2011 o Programa Nacional de Fortalecimento Institucional dos Órgãos Gestores de Cultura, que integrou três projetos: (1) apoio à elaboração de planos estaduais e municipais de cultura; (2) apoio técnico das representações regionais do MinC para o desenvolvimento dos sistemas de cultura; e (3) apoio à formação de gestores de cultura do Nordeste.

O projeto dos planos estaduais e municipais de cultura foi consequência de um longo processo de discussão, iniciado em 2010, quando secretários e dirigentes de órgãos públicos de cultura de Estados e Municípios indicaram ao MinC a necessidade de ações de capacitação e assistência técnica para o desenvolvimento de seus respectivos planos. O embasamento da solicitação estava na própria Lei $n^{\circ} 12.343 / 2010$, que prevê que o Ministério ofereça assistência técnica e financeira aos entes que adiram ao PNC. Assim, foi realizada uma parceria entre o MinC, a Universidade Federal de Santa Catarina (UFSC), a Universidade Federal da Bahia (UFBA) e órgãos públicos gestores de cultura de estados e municípios, que a partir de 2012 iniciaram o projeto de apoio metodológico e técnico para elaboração de planos de cultura. Em síntese, a UFSC ficou responsável por acompanhar o Distrito Federal e os Estados, e a UFBA, os municípios. Vale ressaltar que apesar de as universidades desenvolverem metodologias próprias, ambas deveriam favorecer a participação social, a criação e o uso de instâncias de governança e abranger tanto a dimensão setorial da cultura quanto territorial.

A primeira edição do Projeto de Apoio à Elaboração dos Planos Estaduais 
de Cultura abarcou 17 unidades federadas: o Distrito Federal e 16 Estados, todos signatários do Acordo de Cooperação Federativa do SNC; dentre esses estados estava a Bahia, cujo processo de participação no projeto será analisado a seguir.

\section{Antecedentes do Plano Estadual de Cultura da Bahia}

A formulação do Plano Estadual de Cultura da Bahia (PEC) possui alguns marcos antecessores à participação do Estado no Programa Nacional de Fortalecimento Institucional dos Órgãos Gestores de Cultura, a saber: (1) criação da Secretaria de Cultura do Estado (Secult) em 2006; (2) alinhamento político da Secult com o MinC; e (3) instituição do Sistema Estadual de Cultura da Bahia em 2011.

De 1991 a 2006, o Estado da Bahia foi governado por coligações dirigidas pelo Partido da Frente Liberal (PFL), atual Democratas, que no campo da cultura optou por não dedicar-lhe um órgão gestor exclusivo. Assim, durante mais de uma década, as ações dirigidas a essa área esteve sob o comando da Secretaria de Cultura e Turismo (SCT), o que na opinião de alguns estudiosos implicou em distorções como: subordinação da cultura em relação ao turismo; construção de um discurso de uma identidade baiana voltada para fortalecer o mercado do turismo, negligenciando a diversidade cultural do Estado; e concentração de recursos em Salvador, capital do Estado, e em torno de um grupo pequeno de produtos culturais (CANEDO, 2008; FERNANDES, 2008; RUBIM, 2007).

A relação entre cultura e turismo é complexa e enseja uma série de debates, a exemplo da construção de estereótipos voltados para representar determinada riqueza cultural de uma região/povo (HAZIN, OLIVEIRA, MEDEIROS, 2001) e, mais recentemente, de processos de gentrificação típicos de grandes centros urbanos, onde a preservação de sítios históricos veio acompanhada da apropriação seletiva do espaço, constituindo uma política que tenta conjugar renovação e preservação patrimonial, privilegiando a oferta de infraestrutura e serviços voltados para o turismo e para a ascensão econômica (PAES, 2018). Nesse sentido, o reconhecimento da interface entre cultura e turismo não pode ser desacompanhado de uma reflexão profunda e crítica sob os efeitos das políticas dirigidas a um e a outro. No caso da Bahia, tais políticas conduziram ao provimento de ações culturais da SCT voltadas para:

[...] infraestrutura, através da construção e da manutenção de equipamentos culturais [...], preservação do patrimônio material através do restauro de monumentos históricos e da aquisição de coleções para museus, [...] e dinamização do setor cultural. Privilegiou-se a consolidação de uma marca da identidade baiana, limitada aos recursos culturais da região do Recôncavo, em detrimento da diversidade cultural que caracteriza um Estado com 417 municípios. (CANEDO, 2008, p.71).

A prática dessa política começou a ser alterada em 2006, quando foi publicada em dezembro a Lei $n^{\circ} 10.549$, instituindo a Secretaria de Cultura (Secult), um dos primeiros atos da gestão de Jaques Wagner, governador eleito pelo Partido dos Trabalhadores (PT) nas eleições daquele ano. Em termos organizacionais, a Secult contava com duas superintendências: Superintendência de Promoção Cultural e a Superintendência de Cultura, além das instituições vinculadas: Fundação Pedro Calmon (FPC), Fundação Cultural do Estado da Bahia (Funceb), Instituto do Patrimônio Artístico e Cultural (Ipac) e o Instituto de Rádio Difusão Educativa da Bahia (Irdeb). Em termos de orientação político-conceitual, a Secult buscou atuar a partir das seguintes linhas: diversidade, desenvolvimento, descentralização, democratização e diálogo/transparência; e apresentou como missão:

Formular e implementar, de forma articulada com a sociedade, políticas pú- 
blicas que expressem a centralidade da cultura na transformação e no desenvolvimento social e valorizem a diversidade cultural da Bahia, nas suas dimensões territorial, simbólica, econômica e de cidadania. (BAHIA, 2007)

O trecho citado demonstra a mudança na condução das políticas culturais no Estado e um alinhamento expressivo com a política dirigida pelo MinC, pautada nas dimensões simbólica, econômica e cidadã da cultura. Já a quarta dimensão assumida pela Secult - territorial - foi fundamental na concretização de parcerias entre os dois órgãos gestores. Assim, programas e projetos federais implantados na Bahia foram adapta- dos seguindo a política de territorialização do Estado, refletido, por exemplo, na adoção de critérios em editais que estabeleciam cotas de projetos por município e/ou por Território de Identidade, como ocorreu com o Edital de Pontos de Cultura da Bahia de 2008 (ROCHA, 2011). Outra ação que exemplifica a aproximação entre o MinC e a Secult foi as conferências de cultura. Seguindo a dinâmica desse espaço de participação social convocado pelo Ministério (em 2005, 2010 e 2013), a Secult realizou conferências estaduais (em 2005, 2007, 2009, 2011 e 2013) que envolviam etapas municipais e territoriais, e em algumas edições, setoriais. A adesão da Bahia às conferências de cultura é emblemática, conforme quadro a seguir.

\begin{tabular}{|c|c|c|c|c|}
\hline & $\begin{array}{c}\% \text { de municípios } \\
\text { baianos participantes }\end{array}$ & $\begin{array}{c}\text { Quantidade de } \\
\text { inscritos* (aprox.) }\end{array}$ & Tema & $\begin{array}{l}\text { Quantidade } \\
\text { de propostas - } \\
\text { etapa estadual }\end{array}$ \\
\hline $\begin{array}{l}\text { I CEC } \\
2005\end{array}$ & $5 \%$ & $2 \mathrm{mil}$ & $\begin{array}{c}\text { Estado e sociedade } \\
\text { construindo as políticas } \\
\text { públicas de cultura }\end{array}$ & 47 \\
\hline $\begin{array}{l}\text { II CEC } \\
2007\end{array}$ & $93,5 \%$ & $41 \mathrm{mil}$ & Cultura é o que? & 394 \\
\hline $\begin{array}{l}\text { III CEC } \\
2009\end{array}$ & $88,4 \%$ & $50 \mathrm{mil}$ & $\begin{array}{c}\text { Cultura, diversidade, cidadania } \\
\text { e desenvolvimento }\end{array}$ & $\begin{array}{c}32 \text { (16 para a etapa } \\
\text { Estadual e } 16 \text { para } \\
\text { a Nacional) }\end{array}$ \\
\hline $\begin{array}{c}\text { IV } \\
\text { CEC } \\
2011\end{array}$ & $73 \%$ & $30 \mathrm{mil}$ & $\begin{array}{c}\text { Planejar é preciso - } \\
\text { consolidação dos planos de } \\
\text { cultura }\end{array}$ & 76 \\
\hline $\begin{array}{l}\text { V CEC } \\
2013\end{array}$ & $85,8 \%$ & $45 \mathrm{mil}$ & $\begin{array}{c}\text { Uma política de Estado para a } \\
\text { cultura: desafios do Sistema } \\
\text { Estadual de Cultura }\end{array}$ & $\begin{array}{c}30 \text { (20 para a etapa } \\
\text { Estadual e } 10 \text { para } \\
\text { a Nacional) }\end{array}$ \\
\hline
\end{tabular}

Quadro 01 - Comparativo das conferências estaduais de Cultura da Bahia

* Considerando o total de participantes ao longo de todas as etapas das conferências. 
Os temas que conduziram as conferências de cultura revelam o alinhamento da Secult com o MinC, notadamente relativas ao Plano de Cultura e ao Sistema de Cultura, conforme as conferências de 2011 e 2013; mas refletem também um processo de institucionalização de tais elementos que vinham sendo desenvolvidos no Estado, e que foi materializado com a aprovação da Lei $n^{\circ} 12.365$, de 30 de novembro de 2011. A chamada Lei Orgânica da Cultura da Bahia estabelece os objetivos e princípios orientadores da política estadual de cultura e institui o Sistema Estadual de Cultura da Bahia enquanto

[...] conjunto articulado e integrado de normas, instituições, mecanismose instrumentos de planejamento, fomento, financiamento, informação, formação, participação e controle social, que tem como finalidade a garantia da gestão democrática e permanente da Política Estadual de Cultura nos termos desta Lei. (BAHIA, 2011)

O quadro 02 apresenta a composição desse Sistema.

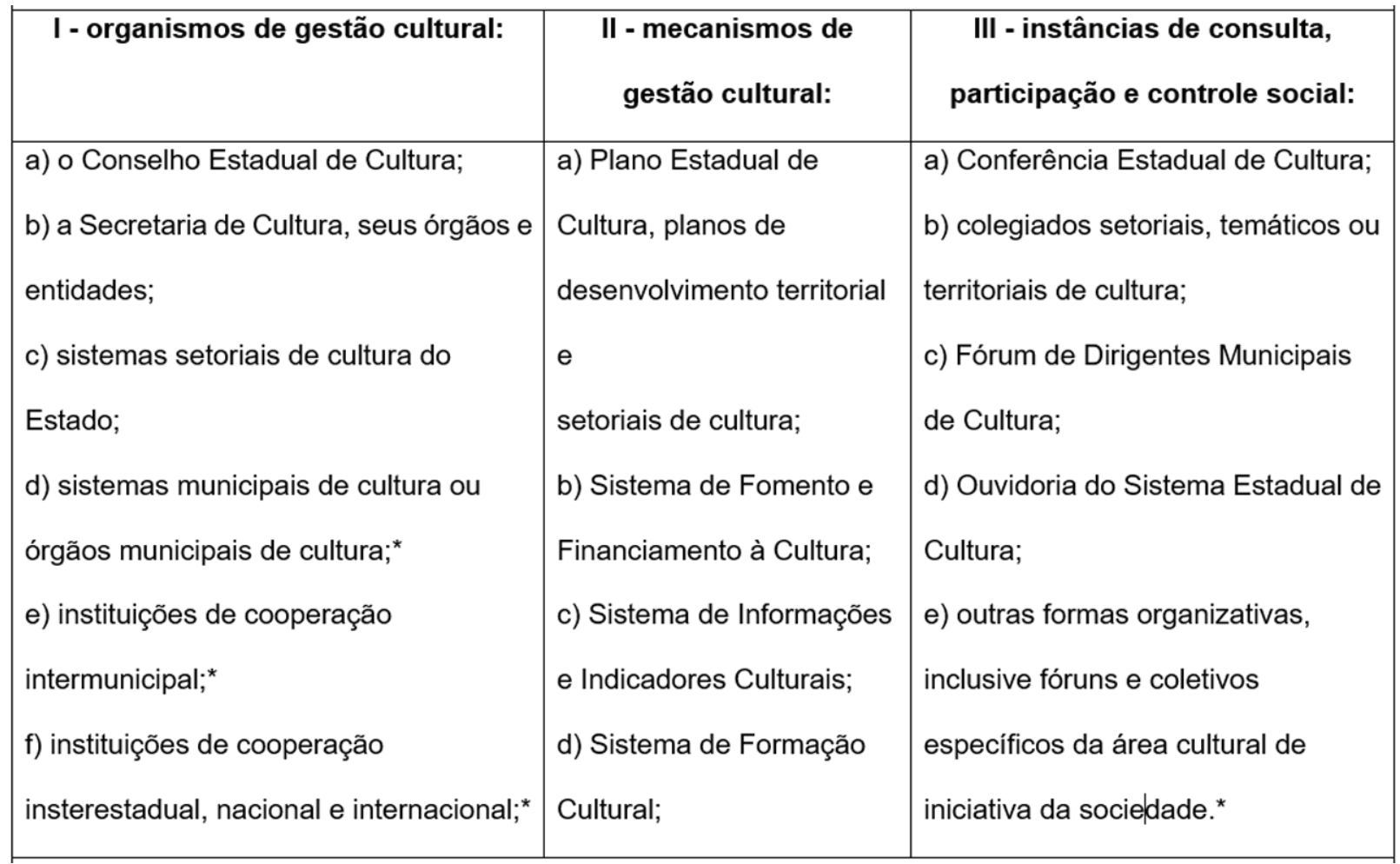

Quadro 02 - Composição do Sistema Estadual de Cultura da Bahia *De acordo com o parágrafo único do artigo sétimo, esses organismos e instâncias devem integrar o SEC
em instrumento jurídico próprio, definido em regulamento.

Fonte: elaboração da autora a partir de informações disponibilizadas na Lei Estadual n Lei n 12.365/2011.

Em comparação com o SNC, vale ressaltar que o Sistema de Cultura da Bahia foi instituído um ano antes, já que a Emenda Constitucional n 71 que acrescentou o Art. 216-A à Constituição Federal só foi aprovada em novembro de 2012. Em termos de composição, observa-se que o Sistema Estadual incorpora 
mais instâncias de consulta, participação e controle social que o SNC, prevendo existência do Fórum de Dirigentes Municipais de Cultura; Ouvidoria e abrindo ainda para novas formas organizativas. Além disso, pode ser composto também por instituições de cooperação de diversos âmbitos, inclusive internacional.

Especificamente em relação ao Plano Estadual de Cultura, o artigo 15 da Lei Orgânica o descreve como mecanismo de gestão cultural de caráter obrigatório que deve orientar a formulação do Plano Plurianual, dos planos territoriais e setoriais, além do Orçamento Anual. A Lei estabelece ainda a estrutura do PEC - diagnóstico; diretrizes; estratégias, metas e ações; políticas específicas, inclusive setoriais e territoriais, de fomento e de qualificação; fontes de financiamento etc. -, as responsabilidades e as condições para sua aprovação, a exemplo de: (1) periodicidade mínima decenal; (2) ser elaborado com participação social, devendo considerar as proposições da Conferência Estadual de Cultura e o conteúdo do PNC; (3) contar com a participação e o controle social no momento da formulação, execução, acompanhamento e avaliação; (4) ter o processo de elaboração coordenado pela Secult, cabendo ao Conselho Estadual de Cultura a sua apreciação e deliberação para que o mesmo seja, por fim, encaminhado à Assembleia Legislativa.

O conjunto de todas essas iniciativas apresentadas nessa sessão é fundamental para compreender o processo de ingresso e participação da Bahia no projeto de apoio à elaboração de planos estaduais de cultura do MinC.

\section{A elaboração do Plano Estadual de Cultura da Bahia}

Em março de 2012, a Secult firmou Termo de Compromisso com o MinC e a UFSC dirigido à elaboração do Plano Estadual de Cultura da Bahia. De acordo com esse documento, o Ministério deveria indicar as diretrizes gerais do projeto e supervisionar o plano de trabalho; à UFSC caberia dar condições técnicas para o desenvolvimento das atividades de elaboração do plano junto aos Estados; e à Secult prover condições para a construção do mesmo por meio de medidas como: acolhimento de técnicos; acesso a documentos; garantia do processo de construção participativa etc. A vigência do Termo era de 12 meses, prazo que se mostrou inexequível para a tramitação completa do Plano: do diagnóstico à aprovação na Assembleia Legislativa do Estado. Nesse sentido, a Secretaria continuou trabalhando no documento ao longo de 2013, 2014 e 2015.

O trabalho de elaboração do PEC foi conduzido pelo "Núcleo Executivo Estadual", composto por um articulador, funcionário da Secult, e por dois técnicos contratados após indicação da Secretaria e análise curricular da UFSC, sendo uma coordenadora técnica e um analista técnico em gestão cultural. Ao longo de dois anos, esse Núcleo se dedicou à formulação do Plano com apoio de dirigentes e servidores da Secult, incluindo o próprio Secretário, Albino Rubim, que considerava essa ação prioritária para a gestão pública e Ihe dedicou acompanhamento direto. Para Rubim (2014, p.6), era preciso fortalecer a institucionalidade da cultura por meio da criação de legislações vinculadas a demandas sociais e disputas político-culturais.

A institucionalidade cultural ainda é muito frágil na Bahia, no Brasil e no mundo. A confecção de legislações qualificadas tem um papel essencial na conformação de um ambiente adequado que estimule e garanta o fortalecimento da cultura. A legislação é uma das dimensões mais substantivas da institucionalidade. Ela baliza e dá regra e compasso para a cultura. Uma legislação qualificada 
e progressista estimula sobremodo o campo cultural e seu desenvolvimento.

Nesse sentido, o PEC integrava a pretensão de fortalecimento da Secult e da própria política cultural do Estado.

Um dos primeiros desafios enfrentados pelo Núcleo Executivo Estadual foi avaliar a proposta metodológica da UFSC, já que era preciso adequá-la à situação do Estado, possuidor de antecedentes que não podiam ser ignorados. Sabia-se que vários Estados haviam firmado o Termo de Compromisso com a UFSC e o MinC e que era preciso garantir algum grau de independência em relação à metodologia geral proposta pela Universidade. As condições de implantação do SNC variavam de um lugar para outro, a exemplo da existência de órgão gestor exclusivo para a cultura em alguns estados; funcionamento e composição de conselho de cultura; e existência de sistema estadual de cultura, caso da Bahia e do Acre. Especificidades desse tipo devem ser alvo de constante preocupação em uma política que se proponha sistêmica e fomentadora do pacto federativo, como é o caso do SNC. Para Barros e Machado (2013), o alinhamento institucional e formal em torno da construção de um sistema federativo deve respeitar as singularidades culturais e regionais. Nesse sentido, apesar de o importante alinhamento entre os planos estaduais de cultura e o PNC, é preciso garantir espaços para que os entes subnacionais possam instituir seus processos e dinâmicas respeitando suas especificidades.

No caso da Bahia, tais singularidades foram respeitadas e assimiladas ao longo do diálogo com a UFSC, cuja metodologia era pautada em quatro etapas: (1) sensibilização e mobilização dos atores sociais chave e articulação de parceiros; (2) análise situacional da realidade do setor cultural; (3) prognóstico para o futuro do setor cultural; e (4) sistema de monito- ramento e avaliação do plano estadual de cultura (UFSC, 2012).

O objetivo principal da primeira fase era criar e fomentar processos de participação social. Para isso, era indicado a criação de um fórum estadual e de fóruns regionais. Ao Núcleo Executivo Estadual caberia coordenar tal trabalho, envolvendo também a formação dos participantes, levantamento de informações sobre as regiões/territórios, realização de oficinas e seminários etc. Como a Bahia já havia iniciado o processo de formulação do seu PEC, especialmente considerando a IV Conferência Estadual de Cultura, ocorrida um ano antes do início desse projeto, a Secult decidiu não criar os fóruns indicados pela UFSC. A IV CEC, conforme Quadro 01, teve por tema a elaboração de planos de cultura; a sua mobilização foi intensa, envolvendo aproximadamente 30 mil pessoas, entre representantes da sociedade civil e do poder público; em termos territoriais, a abrangência da IV CEC foi grande, com participação dos 27 territórios de identidade (100\%) e 307 municípios (73\%). Considerando esse contexto, criar novas instâncias de discussão para levantar as prioridades para o PEC poderia deslegitimar a Conferência, fragilizando o processo de participação social iniciado em 2005. Nesse sentido, a Secult optou por reconhecer as Conferências enquanto espaço fundamental na formulação de políticas públicas e por potencializar instâncias de diálogo já existentes. Asssim, manteve-se ao longo do projeto relação especial de proximidade com o Conselho Estadual de Cultura, na época composto exclusivamente por representantes da sociedade civil. Além disso, foram realizados encontros com integrantes dos Pontos de Cultura da Bahia; com representantes de órgãos públicos municipais da cultura, por meio da Associação de Dirigentes Municipais de Cultura, e com servidores e dirigentes que ocupavam lugar estratégico na Secult, a exemplo dos Representantes Territoriais 
da Cultura (funcionários que atuavam nos Territórios de Identidade).

A segunda fase do projeto - análise situacional da realidade do setor cultural tinha por objetivo reunir informações para construção de um diagnóstico, auxiliando a indicação das prioridades para o PEC. Para tanto, o Núcleo Executivo, com apoio de outros setores da Secretaria, reuniu informações das quatro conferências de cultura e dos relatórios de gestão da Secult, além de dados do IBGE, do IPEA, da Superintendência de Estudos Econômicos e Sociais da Bahia e da Secretaria Estadual da Fazenda. Esse conjunto de informações foi estruturado em torno das dimensões simbólica, cidadã e econômica da cultura, e de aspectos relativos à gestão cultural e à participação social, em sintonia com a organização do PNC. Dessa etapa vale ressaltar que foram encontradas diversas limitações, pois os dados sobre a cultura no Estado eram insuficientes e estavam dispersos. A fragilidade e falta de sistematização de informações que acomete a área da cultura não é novidade e nem exclusividade da Bahia. Na esfera federal, somente a partir dos anos 2000 é que o IBGE passou a gerar dados sobre a área, após acordo firmado com o MinC durante a gestão do ministro Gilberto Gil. É sabido que a elaboração de políticas públicas deve considerar estudos e pesquisas que ajudem a definir diretrizes e prioridades, evitando o desperdício de gastos e esforços. Entretanto, os instrumentos de gestão, como os planos de cultura, ainda possuem seus diagnósticos fragilizados. Ao analisar o PNC, Albino Rubim (2008) destaca justamente a fragilidade e fragmentação de seu diagnóstico, que não conseguiu delimitar com precisão os problemas a serem atacados, refletindo na dispersão do documento. No caso do PEC, apesar do esforço de indicar os pontos fracos e fortes do setor cultural do Estado, o diagnóstico nem sempre conseguiu apresentar com seguridade o que precisava, de fato, ser realizado.
"Prognóstico para o futuro do setor cultural" era a terceira fase do projeto, cujo objetivo era traçar estratégias para alcançar os resultados pretendidos, em sintonia com o diagnóstico. Era o momento de definir as diretrizes, objetivos, estratégias, metas e ações do plano, incluindo os prazos de execução e a previsão de recursos. Tais elementos estavam em consonância com as exigências da Lei Orgânica da Cultura da Bahia, que ressaltava ainda a necessidade de serem consideradas as conferências de cultura e o PNC. Diante disso, o Núcleo Executivo começou o trabalho reunindo todas as propostas eleitas como prioritárias nas quatro conferências estaduais de cultura, perfazendo análise de aproximadamente 550 propostas. Esse grande número de demandas prioritárias pode ser interpretado como uma vontade do poder público de contemplar a maior quantidade possível de ideias e de atores culturais, evitando atritos entre esses. Porém, essa postura agregadora dificultou a indicação objetiva das prioridades para a política cultural do Estado, e ao final, as demandas eram tantas que se tornou impossível identificar o que realmente deveria ser prioritário para a área. Converter as demandas de conferências em diretrizes/ estratégias da política cultural é um desafio a ser enfrentado. De maneira geral, as conferências expressam necessidades e desejos, mas desconsideram aspectos fundamentais da gestão, como expectativa de recursos orçamentários, prazos, meios de acompanhamento e avaliação (VILUTIS, 2012). Além disso, os resultados das conferências muitas vezes não originam políticas públicas, já que não há dispositivos, métodos ou mecanismos institucionalizados que assegurem tal desdobramento (ZIMBRÃO, 2013).

No caso da Bahia, muitas propostas apresentadas nas conferências estaduais foram eliminadas do PEC, já que era impossível formular um documento de gestão com periodicidade decenal capaz de 
absorver todas aquelas demandas. Para Albino Rubim, apesar de o PEC ter considerado os resultados das conferências,

[...] Isto não significa, honestamente, que todas as propostas aprovadas nas conferências tenham sido ou possam ser implantadas. As demandas são muitas, diversas, algumas exigem recursos vultosos e outras são contraditórias, como é natural em um ambiente democrático (RUBIM, 2013a, p.3).

Para selecionar as propostas que poderiam compor o Plano, o Núcleo Executivo precisou analisar individualmente cada uma delas, observando uma série de critérios, tais como: consonância com os princípios do Sistema Estadual de Cultura; compatibilidade com o PNC; competência do órgão demandado; capacidade de execução considerando tempo e recurso. $O$ trabalho de interpretar, analisar e compilar as contribuições das conferências gerou um documento com 233 propostas, que obviamente necessitava ser reduzido para tornar-se exequível. Nesse sentido, foi criado um Grupo de Trabalho (GT) composto por representantes da Secult que atuou no estabelecimento de prioridades a partir da aplicação do método GUT. O fato desse GT ser composto por funcionários das várias áreas da Secretaria favoreceu o surgimento de temas não discutidos nas conferências e que foram incorporados no PEC, a exemplo da estratégia 2 - "Aprimoramento de gestão de políticas públicas", que tem como uma das ações "b) fortalecer os quadros institucionais e carreiras da Secretaria de Cultura, otimizando o emprego de recursos e garantindo o exercício de suas competências" e a meta

$70 \%$ do quadro de pessoal da Secretaria formado por servidores efetivos estatutários. Realização de concursos públicos, em especial, para profissionais especializados. Plano de carreira dos servidores da Cultura reformado em 2015 e implantado em 2016.
Esse GT favoreceu também o debate sobre a necessidade de ações complementares entre os setores da Secult. Por exemplo, algumas propostas das conferências eram dirigidas à memória dos povos tradicionais e necessitava da atuação conjunta do IPAC e do Centro de Culturas Populares e Identitárias (CCPI). Vale ressaltar que além do distanciamento entre as unidades vinculadas, havia um certo afastamento dessas com o órgão central da Secretaria, daí a necessidade da "superação deste esgarçamento institucional e o desenvolvimento de políticas compartilhadas". (RUBIM, 2013b, p. 176) Todo esse trabalho ensejou um debate fundamental sobre como as questões setoriais seriam incorporados ao Plano, o que levou à decisão de não incluí-las, deixando-as para os seus respectivos planos setoriais. Desse modo, o PEC não estabelece ações específicas para o teatro, o museu, a música ou a leitura. $O$ documento traz estratégias mais amplas, capazes de abarcar diversas áreas, a exemplo da estratégia 13:

Desenvolvimento e ampliação dos espaços culturais existentes na Bahia, inclusive os da Secretaria de Cultura do Estado, através das seguintes ações: a) ampliar e diversificar as ações de formação e fidelização de público, qualificando a fruição e o contato com as culturas; b) promover a disponibilização de repertórios, de acervos, de documentos e de obras de referência. (BAHIA, 2014)

Outro desdobramento do trabalho desse GT foi a identificação de várias demandas das conferências que não eram da competência direta da Secult, mas que eram fundamentais para a área da cultura, a exemplo de propostas voltadas para educação e comunicação. Nesse sentido, o PEC dedicou uma sessão para tratar da transversalidade da cultura com outras áreas, estabelecendo no parágrafo sétimo, estratégia 20: 
Promoção da articulação das políticas públicas de cultura com as de outras áreas governamentais, através das seguintes ações:

[...] b) atuar em conjunto com os órgãos de educação no desenvolvimento de atividades que insiram a cultura no ensino regular como instrumento e tema de aprendizado, com a finalidade de estimular o olhar crítico e a expressão artístico-cultural do estudante; [...]

e) promover o turismo cultural sustentável, aliando estratégias de preservação patrimonial e ambiental com ações de dinamização econômica e fomento às cadeias produtivas da cultura; [...]

f) realizar programas, em parceria com os órgãos de comunicação, para que atuem como centro de produção e difusão cultural;

g) implantar, em conjunto com os órgãos responsáveis, a banda-larga em todo Estado da Bahia; [...] (BAHIA, 2014)

Finalizado o trabalho desse GT, coube ao Núcleo Executivo compatibilizar as prioridades pré-definidas para 0 PEC com as previstas no PNC. Assim, se a meta 2 do PNC prevê " $100 \%$ das Unidades da Federação (UF) e 60\% dos municípios atualizando o Sistema Nacional de Informações e Indicadores Culturais (SNIIC)" (BRASIL; MINC, 2012), o PEC a incorporou nos seguintes termos:

Art. $9^{\circ}$, III - estratégia 3 - Implantação do Sistema de Informações e Indicadores Culturais como instrumento de acompanhamento, avaliação e aprimoramento da gestão e das políticas públicas de cultura, através das seguintes ações:

a) cadastrar, mapear e sintetizar as informações culturais, a fim de orientar a coleta pelo Estado e Municípios de dados relacionados à gestão, formação, produção, difusão, circulação, fruição e reflexão de obras, atividades e expressões culturais; b) estabelecer parâmetros para formulação, implementação, gestão, monitoramento e avaliação das políticas culturais. (BAHIA, 2014)

Várias outras iniciativas foram absorvidas pelo PEC e a sua própria estrutura buscou refletir a organização do PNC. Outra similaridade entre os dois refere-se à elaboração posterior das metas, ou seja, após a publicação como lei dos Planos. No caso do PNC, ele foi instituído por lei em 2010 e suas metas publicadas em dezembro de 2011. No caso do PEC, ele foi aprovado como lei em novembro de 2014 e suas metas submetidas a consulta pública entre dezembro de 2014 e março de 2015. O Projeto de Lei do PEC, portanto, não apresentou metas, sendo composto por 12 princípios, 19 objetivos, 7 diretrizes, distribuídas em sete capítulos, 20 estratégias e 62 ações.

A minuta do PEC foi submetida a consulta pública, via internet, entre os dias 15 de agosto e 30 de setembro de 2013, cabendo sugestões de alterações em todo o documento. Ao final foram registradas 133 contribuições, sendo quase todas comentários ou relatos sobre determinado tema. Não foi sugerido exclusão de conteúdo e das inclusões sugeridas, seis foram inseridas no documento, que seguiu para apreciação do Conselho Estadual de Cultura. De acordo com a Lei Orgânica da Cultura, a aprovação e deliberação do PEC cabia ao Conselho e, seguindo a determinação, a Secult encaminhou aos conselheiros a minuta comentada do Plano, ressaltando as contribuições da consulta pública, e o diagnóstico. A reunião de deliberação foi realizada na sede do Conselho ao longo do dia 05 de novembro de 2013 e contou a presença do secretário e alguns dirigentes da Secult, do Núcleo Executivo do Plano, e dos próprios membros do Conselho. Do debate nesse plenário vale destacar a alteração de duas propostas incluídas após a consulta pública: "Garantir formação periódica aos conselheiros de cultura" e "Garantir a for- 
mação dos membros que integram os Fundos de Cultura". Por decisão dos conselheiros, essas ações passaram a ser redigidas como: "Garantir assessoria técnica aos conselhos de cultura" e "Garantir assessoria técnica aos membros que integram os Fundos de Cultura". No entendimento dos conselheiros não eram necessárias ações de formação para tal função, já que aqueles que tomam posse nessa instância já devem possuí-la, cabendo apenas uma assessoria técnica. Esse posicionamento divergia do que vinha sendo desenvolvido pelo MinC e pela Secult, que defendiam a formação permanente de conselheiros, tanto em temas específicos, como orçamento público, como em questões mais amplas relacionadas à interface entre Estado e sociedade. (FERNANDES; RUBIM; RUBIM, 2010) Apesar dessa divergência, a minuta do PEC foi aprovada em sessão única no Conselho, ressalvadas as críticas quanto à fragilidade do diagnóstico e falta de maior detalhamento do Plano, provavelmente decorrente da ausência das metas.

Especificamente sobre as metas, vale ressaltar que a decisão de não incluí-las nesse momento deveu-se a duas questões. A primeira relativa ao tempo de tramitação do Projeto de Lei do PEC. Até chegar à Assembleia Legislativa, a minuta precisava passar pela consulta pública, ser aprovada pelo plenário do Conselho Estadual de Cultura, voltar para ajustes formais na Secult, ser encaminhada para a Procuradoria Geral do Estado e para a Casa Civil. Considerando que essa tramitação começaria em agosto de 2013, quando findava a consulta pública, e que em 2014 havia eleição para o Governo do Estado, era preciso dar celeridade à elaboração do documento para que pudesse ser aprovado ainda naquela gestão; especialmente considerando que

[...] a política pública ainda está vinculada a acordos político-partidários e pessoais, dificultando que se supe- re a prática instalada de atendimentos pontuais para a sua definição e o desmantelamento de seus quadros técnicos, permitindo a implementação de uma política pública de continuidade (CALABRE; PARDO, 2013, p. 218).

Como as metas requeriam mais tempo para serem elaboradas, optou-se por inseri-las posteriormente. Além disso, na visão do secretário Albino Rubim, a inclusão das metas no Plano aprovado no Legislativo, poderia engessar o documento, visto que para as metas serem revisadas e alteradas, seria necessário submetê-las novamente à aprovação dos deputados estaduais. Nesse sentido, seria mais estratégico separar as metas do documento aprovado como Lei e inseri-las em uma normativa vinculada ao Executivo, a exemplo de um decreto. Por isso, foi estabelecido no projeto de lei do PEC que as suas metas seriam fixadas pela coordenação executiva (composta por membros indicados pela Secult, com a participação do Conselho Estadual de Cultura e representantes do setor cultural), e publicadas em 180 dias, a partir da entrada em vigor da Lei.

Finalmente, em junho de 2014 o Projeto de Lei (PL) 20.864/14 que cria o Plano Estadual de Cultura da Bahia foi enviado em caráter de urgência para a Assembleia Legislativa, onde foi aprovado por unanimidade no dia 05 de novembro desse mesmo ano. O passo seguinte dado pela Secult foi constituir uma comissão para elaborar as metas do PEC, orientadas por três aspectos: (1) considerar o PNC e suas metas, notadamente as que tinham incidência sobre os entes subnacionais; (2) não incluir metas setoriais, já que essas deveriam compor os planos setoriais que estavam em elaboração; (3) serem em número reduzido, considerando a exequibilidade do documento e a existência de outros planos complementares. Ao final, foram elaboradas 20 metas. Parte delas atendiam a diversas estratégias e ações, a exemplo da Meta 1 "Sistema es- 
tadual consolidado com $100 \%$ dos planos setoriais e territoriais elaborados e implantados e sistemas municipais implantados em $60 \%$ dos municípios baianos", que atendia a ações das estratégias 1 - "Fortalecimento da articulação das esferas dos poderes públicos"; 2 - "Aprimoramento da gestão de políticas públicas" e 9 - "Consolidação do Fundo de Cultura como principal mecanismo de fomento". Em outros casos, duas metas atendiam a uma mesma ação, como a que respondia pela estratégia 14, "Estabelecimento de redes de equipamentos culturais", que tinha como primeira ação: "estabelecer sistemas de integração de equipamentos culturais, fomentando, inclusive, programas de amparo e apoio à manutenção e gestão em rede de equipamentos culturais, potencializando investimento e garantindo padrões de qualidade". Para essa ação foram definidas duas metas:

Meta 12 - Instalação e funcionamento de, pelo menos, duas instituições culturais mantidas pelo Governo Federal na Bahia. Implantação de dois novos centros culturais da Secretaria de Cultura em territórios de identidade que não tenham equipamentos culturais da Secretaria. Instalação de, pelo menos, 40 novos centros culturais municipais na Bahia. Atração de, pelo menos, cinco centros culturais mantidos por organizações empresariais.

Meta 13 Implantação e funcionamento de rede de equipamentos culturais públicos - federais; estaduais e municipais - com intercâmbio de experiências, programações compartilhadas e acervos disponibilizados na internet.

Também foram definidas metas que dialogavam diretamente com o PNC, a exemplo de

Meta 17 - Aumento de $200 \%$ de vagas nos cursos de graduação e pós-graduação em cultura, ampliação em 150\% de agentes culturais atendidos por cursos técnicos e profissionalizantes, crescimento em $100 \%$ de agentes culturais atendidos por outros tipos de cursos e aumento de $100 \%$ de agentes culturais atendidos por assessorias técnicas, transformando a Bahia em destino nacional e internacional de formação, qualificação e capacitação em cultura

Ao mesmo tempo em que essa meta atendia à estratégia 18 do PEC "Disseminação do conhecimento e ampliação da apropriação social do patrimônio cultural" -, vinculava-se às metas 15 , 16 e 18 do PNC. Vale registrar que para a implementação dessas metas, a Secult e o MinC precisam se articular com os órgãos públicos de educação.

Esse conjunto de 20 metas elaboradas pela Secult foi submetido a consulta pública entre os dias 12 de dezembro de 2014 e 31 de março de 2015, alcançando, assim, outra gestão.

Finalizado o processo de elaboração do PEC, cabia à Secult implementá-lo, monitorando as metas e realizando os ajustes necessários. Tal processo, entretanto, possui pouca visibilidade, não sendo possível acompanhar a execução do PEC, que sequer tem suas metas divulgadas no site da Secretaria. A avaliação, portanto, do desenvolvimento das ações previstas no Plano por parte de atores não vinculados à Secult fica bastante comprometida.

\section{Considerações Finais}

A análise do processo de formulação do PEC permitiu observar quão complexo é a construção de instrumentos de gestão pública que proponham ser participativos e democráticos; preocupação que permeou a Secult que, a partir de 2006, passou a ter dentre suas diretrizes a participação social e a territorialização da cultura. O PEC, por- 
tanto, deveria estar em consonância com tal orientação e refletir a política desenvolvida no Estado, consolidada formalmente por meio da Lei $n^{\circ} 12.365 / 2011$, que instituiu o Sistema Estadual de Cultura da Bahia. A Lei Orgânica da Cultura, como ficou conhecida, englobava uma série de iniciativas, dentre elas a previsão de planos estaduais, setoriais e territoriais da cultura. Consequentemente, o trabalho de elaboração do PEC deveria estar em consonância fina com os dispositivos dessa Lei. Também deveriam ser incorporados no documento as contribuições oriundas das diversas conferências de cultura realizadas no Estado. Especialmente a partir da II Conferência (2007), houve uma grande mobilização de atores culturais, tanto da sociedade civil como do poder público, em torno da definição de prioridades para a política cultural da Bahia. A Secult entendeu, assim, que o conjunto das demandas elencadas nesses encontros deveriam ser a principal fonte do PEC.

Outra diretriz do processo de formulação do Plano foi a articulação com o PNC. De maneira geral, as duas gestões da Secult - 2007 a 2010 e 2011 a 2014 - estiveram em sintonia fina com as políticas culturais desenvolvidas pelo MinC. Isso pode ser confirmado por diversas iniciativas, a exemplo da instituição do Sistema Estadual de Cultura da Bahia, reflexo do SNC; do Edital Pontos de Cultura da Bahia, o primeiro a ser publicado no país, fruto da estadualização do projeto do MinC; e do empenho do Estado em promover e participar das Conferências Nacionais de Cultura. Portanto, o diálogo entre o PEC e o PNC refletia esse alinhamento.

Em relação ao documento em si, verificou-se que alguns critérios guiaram a sua elaboração, a saber: número limitado de estratégias, ações e metas, inserindo apenas aquelas consideradas imprescindíveis e exequíveis; apresentação de temas centrais, delegando temas setoriais a planos específicos; exclusão de assuntos próprios de determinados municípios ou territórios, já que as ações do PEC deveriam ser pertinentes ao todo o Estado e questões territoriais/municipais deveriam estar em seus respectivos planos; indicação de ações transversais, ainda que não fossem de competência exclusiva da SEC, a exemplo de matérias relativas à educação ou à comunicação, fundamentais para o desenvolvimento da cultura; e alinhamento com as metas do PNC.

Destaca-se nesse processo a opção da Secult de não incluir as metas no Projeto de Lei do PEC, aprovado pela Assembleia Legislativa do Estado em novembro de 2014. As metas são fundamentais em um plano, conferindo-lhe concretude, viabilidade orçamentária e acompanhamento sistemático. A questão é se, garantida a participação social, elas devem ser submetidas a aprovação e revisão do Legislativo ou se devem ficar restritas ao Executivo. É uma discussão que merece ser aprofundada. As metas são monitoradas e devem sofrer alterações ao longo da execução do PEC; são, portanto, mais flexíveis que outros elementos, como objetivos ou diretrizes, e, assim, podem ser modificadas com mais celeridade, nada garantido se tramitar no Legislativo. Por outro lado, a não fixação em Lei das metas pode prejudicar a implementação do Plano por parte do próprio Executivo, que, por exemplo, pode não divulgá-las ao conjunto da sociedade. Vale o debate.

Por fim, é impossível abordar esse assunto sem fazer uma mínima referência à situação atual do Brasil. A extinção do Ministério da Cultura e toda fragilização que as políticas culturais vem sofrendo nos últimos anos tem desdobramentos graves para a gestão cultural em todos os níveis de governo. O Sistema Nacional de Cultura, que por sua própria configuração de política de médio e longo prazo, requer investimento permanente, necessita estar na pauta dos governos federal, estaduais e municipais; o PNC, cuja vigência termina em 2020, precisa ser renovado com participação social; as Conferências Nacionais de Cultura ne- 
cessitam ser retomadas, já que a última foi realizada em 2013 e novos diálogos entre Estado e sociedade precisam ser instituídos; o sistema de financiamento à cultura precisa ser revisto, e o Fundo Nacional de Cultura ser fortalecido para que viabilize, por exemplo, execução do próprio Plano Nacional. Apesar de todas essas necessidades, o horizonte não é nada animador no país, com uma gestão no âmbito federal completamente avessa a políticas participativas, democráticas e republicanas. Resta saber se haverá resistência e contraposição nas esferas estaduais e municipais e dos atores sociais que vivenciaram a construção participativa de políticas públicas para a cultura.

\section{Referências}

ANDERSON, G. Federalismo: uma introdução. Rio de Janeiro: Editora FGV, 2009.

ARRETCHE, M. Estado federativo e políticas sociais: determinantes da descentralização. 3. ed. Rio de Janeiro: Revan ; São Paulo: FAPESP, 2011.

BARACHO, J. O. Teoria Geral do federalismo. Rio de Janeiro: Forense, 1986.

BAHIA. Lei Estadual No 10.549 de 28 de dezembro de 2006. Modifica a estrutura organizacional da Administração Pública do Poder Executivo Estadual e dá outras providências. Disponível em: https://governo-ba.jusbrasil.com.br/legislacao/85395/lei-10549-06. Acesso em: out. 2019.

BAHIA. Lei Estadual No 12.365 de 30 de novembro de 2011. Dispõe sobre a Política Estadual de Cultura, institui o Sistema Estadual de Cultura, e dá outras providências. Disponível em: http://www. cultura.ba.gov.br/wp-content/uploads/2010/06/Lei12.365-de-30-11-2011-LeiOrg\%C3\%A2nica-daCultura.pdf . Acesso em: 10 mai. 2014.

BAHIA. Projeto de Lei ${ }^{\circ} 20.864 / 2014$. Aprova o Plano Estadual de Cultura da Bahia e dá outras providências. Diário Oficial do Estado da Bahia, Poder Legislativo, Salvador, BA, 3 jun. 2014. Seção 3. p. 9-14.
BARROS, J. M. e MACHADO, F. O Acre e o Brasil: continuidades e singularidades nas políticas culturais, in: BARBALHO, A.; BARROS, J.M., e CALABRE, L. (orgs.), Federalismo e políticas culturais no Brasil. Salvador: Edufba, 2013. p. 43-74.

BRASIL. Constituição (1988). Constituição da República Federativa do Brasil. Brasília,DF: Senado, 1988.

BRASIL. Constituição (1988). Emenda constitucional $\mathrm{n}^{\circ} 48,10$ de agosto de 2005. Acrescenta o $\S 3^{\circ}$ ao art. 215 da Constituição Federal, instituindo o Plano Nacional de Cultura. Diário Oficial [da] República Federativa do Brasil, Brasília, DF, 11 ago. 2005. Seção 1, p. 1. Disponível em: http:// www.planalto.gov.br/ccivil_03/constituicao/emendas/emc/emc48.htm. Acesso em: 11 mar. 2014.

BRASIL. Constituição (1988). Emenda constitucional $n^{\circ} 71$, de 29 de novembro de 2012. Diário Oficial [da] República Federativa do Brasil, Brasília, DF, 30 nov. 2012. Seção 1, p. 1. Disponível em: em: https://www.senado.leg.br/atividade/const/ con1988/EMC71_29.11.2012/EMC71.asp. Acesso em: set. 2019.

BRASIL. Lei no 12.343, de 2 de dezembro de 2010. Institui o Plano Nacional de Cultura - PNC, cria o Sistema Nacional de Informações e Indicadores Culturais - SNIIC e dá outras providências. Diário Oficial [da] República Federativa do Brasil, Brasília, DF, 3 dez. 2010. Seção 1. Disponível em: http:// www.cultura.gov.br/documents/10907/963783/ Lei+12.343++PNC.pdf/e9882c97f62a-40de-bc748dc694fe777a. Acesso em: 10 out. 2015.

BRASIL. Lei n 8.080 , de 19 de setembro de 1990. Dispõe sobre as condições para a promoção, proteção e recuperação da saúde, a organização e o funcionamento dos serviços correspondentes e dá outras providências. Diário Oficial [da] República Federativa do Brasil, Brasília, DF, 19 set. 1990. Disponível em: http://www.planalto.gov.br/ ccivil_03/leis/L8080.htm. Acesso em: 29 nov. 2016.

BRASIL. MINISTÉRIO DA CULTURA. As metas do Plano Nacional de Cultura. Brasília, DF: Ministério da Cultura, 2012.

CALABRE, L; PARDO, A. L. Avanços e desafios do federalismo na cultura do Estado do Rio de Janeiro. In: BARBALHO, A; BARROS, J. M.; CALABRE, L. (orgs.). Federalismo e politicas culturais no Brasil. Salvador: EDUFBA, 2013. p. 201-222.

CANEDO, D. Cultura, democracia e participação social: um estudo da II Conferência Estadual de 
Cultura da Bahia. Dissertação apresentada ao Programa Multidisciplinar de Pós-Graduação em Cultura e Sociedade, Faculdade de Comunicação. Salvador: Universidade Federal da Bahia, 2008.

CUNHA FILHO, F. H. Federalismo Cultural e Sistema Nacional da Cultura: contribuições ao debate. Fortaleza: Edições UFC, 2010.

FERNANDES, T. A Secretaria da Cultura e Turismo do Estado da Bahia 1995-2006. Dissertação apresentada ao Programa Multidisciplinar de PósGraduação em Cultura e Sociedade, Faculdade de Comunicação. Salvador: Universidade Federal da Bahia, 2008.

FERNANDES, T; RUBIM, A; RUBIM, L. (orgs.). Políticas culturais, democracia e conselhos de cultura. Salvador: EDUFBA, 2010.

HAZIN, A. L.; OLIVEIRA, C. de; MEDEIROS, R. P. de. Cultura e Turismo: interação ou dominação? Trabalhos para Discussão. N.121/2001. Disponível em: http://www.fundaj.gov.br/tpd/121.html. Acesso em: ago. 2010.

MINISTÉRIO DA CULTURA; SECRETARIA DE CULTURA DA BAHIA; UNIVERSIDADE FEDERAL DE SANTA CATARINA. Termo de compromisso e assistência técnica. Compromisso que entre si firmaram o Ministério da Cultura, por intermédio da secretaria de articulação institucional, o Estado da Bahia, por intermédio da Secretaria de Cultura, e a Universidade Federal de Santa Catarina para desenvolver o Projeto de apoio à elaboração dos planos estaduais de cultura. Brasília, DF: 2011.

PAES, M. T. (2018). Gentrificação, preservação patrimonial e turismo: os novos sentidos da paisagem urbana na renovação das cidades. GEOUSP Espaço e Tempo (online), 21(3), p. 667-684. https://doi.org/10.11606/issn.2179-0892. geousp.2017.128345

ROCHA, S. C. Programa Cultura Viva e seu processo de estadualização na Bahia. 233 f. Dissertação (Mestrado) - Faculdade de Comunicação, Universidade Federal da Bahia, 2011. Disponível em: https://repositorio.ufba.br/ri/bitstream/ri/16299/1/ Disserta\%C3\%A7\%C3\%A3o_Sophia\%20 Rocha. pdf. Acesso em: 20 nov. 2014.

ROCHA, S. C. Da Imaginação à Constituição: a trajetória do Sistema Nacional de Cultura de 2002 a 2016. 523 f. Tese (Doutorado) - Instituto de Humanidades, Artes e Ciências Prof. Milton Santos, Universidade Federal da Bahia, 2018. Disponível em: http://repositorio.ufba.br/ri/handle/ri/28182. Acesso em: 06 out. 2019.

RUBIM, A. A. C. Políticas culturais no Brasil: tristes tradições, enormes desafios. In: RUBIM, A. (org.). Politicas Culturais no Brasil. Salvador: EDUFBA, 2007. p.11-36.

RUBIM, A. A. C. Plano Nacional de Cultura em debate. Políticas Culturais em Revista, Salvador, v. 1, n. 2, p. 59-72, 2008. Disponível em: https:// portalseer.ufba.br/index.php/pculturais/article/ view/3333/2449. Acesso em: 11 jun. 2018.

RUBIM, A. A. C. V Conferência Estadual de Cultura da Bahia. 2013a. Disponível em: https://conferenciadecultura.files.wordpress.com/2013/06/ texto-do-secretc3a1 rio-de-cultura-da-bahia-albino-rubim-v-conferc3aancia1.pdf. Acesso em: 02 jul. 2014.

RUBIM, A. A. C. Políticas culturais na Bahia contemporânea. In: BARBALHO, A; BARROS, J. M.; CALABRE, L. (orgs.). Federalismo e politicas culturais no Brasil. Salvador: EDUFBA, 2013b. p.159-178.

RUBIM, A. A. C. Apresentação. Legislação e Institucionalidade da Cultura. In: BAHIA. SECRETARIA DE CULTURA DO ESTADO DA BAHIA. Legislação da Cultura na Bahia. 2014 P.5-8. Disponível em: http://www.cultura.ba.gov.br/arquivos/File/publicacaolegislacaodaculturanabahia.pdf. Acesso em: out. 2019.

UNIVERSIDADE FEDERAL DE SANTA CATARINA. Planos estaduais de cultura: estratégias metodológicas para um processo participativo. In: Seminário de Planos Estaduais de Cultura, 2012 Florianópolis. Anais... Santa Catarina: Universidade Federal de Santa Catarina, 2012.

VARELLA, Guilherme. Plano Nacional de Cultura: direitos e políticas culturais no Brasil. Rio de Janeiro: Azougue, 2014.

VILUTIS, Luana. Planos Municipais de Cultura e participação social no fortalecimento de políticas culturais. Políticas Culturais em Revista, Salvador, v.5, n.2, p. 135-150, 2012. Disponível em: https://portalseer.ufba.br/index.php/pculturais/article/view/6751. Acesso em: 12 nov. 2017

ZIMBRÃO, A. Conferências Nacionais de Cultura e seus desdobramentos em políticas públicas. In: Seminário Internacional Políticas Culturais, 4.; 2013, Rio de Janeiro. Anais... Rio de Janeiro: Fundação Casa de Rui Barbosa, 2013. p. 1-16. 